\title{
Crise Migratória na Europa em 2015 e os Limites da Integração Europeia: uma abordagem multicausal
}

\author{
Europe's Migrant Crisis in 2015 and the European Integration Limits: a multicausal \\ approach
}

\section{Carlos Nogueira da Costa Júnior ${ }^{1}$}

\section{RESUMO}

O presente artigo analisa, em uma perspectiva multicausal, a atual crise migratória na Europa, considerando o contexto nos países emissores e receptores, os fatores intervenientes e o arranjo normativo na União Europeia, indicando no conflito entre soberania e direito comunitário um traço fundamental da crise.

Palavras-chave: Migrações Internacionais; Crise Migratória; Europa

\begin{abstract}
This article studies under a multicausal approach the current Europe's migrant crisis, considering the sending and receiving countries scene, the intervening variables and the European Union's legal framework, suggesting that the struggle between sovereignty and Community law is a crisis's pivotal aspect.
\end{abstract}

Key-words: International Migrations; Migrant Crisis; Europe

\section{INTRODUÇÃO}

As migrações internacionais ao longo da história humana evidenciam diferentes contextos e condicionantes, que repercutem variadas perspectivas e diversas reações, conflitando zonas emissoras de pessoas e zonas receptoras. Contudo, no ainda recente século XXI, a complexidade da economia internacional e suas cadeias globais de valor, a instabilidade política em determinadas regiões, bem como as diferentes plataformas jurídicas no tratamento da pessoa humana exercem um papel significativo para compreender o fenômeno migratório.

Nessa instância e considerando os fatores brevemente supracitados, o presente artigo tem como problema central: qual é a natureza da recente crise migratória na Europa, instalada em 2015, e seus reflexos políticos para a posição e a dinâmica da

\footnotetext{
${ }^{1}$ Mestre em Relações Internacionais pela Universidade de Brasília (UnB), Coordenador do Curso de Graduação em Relações Internacionais do Centro Universitário do Distrito Federal (UDF), Brasília, Brasil. Conjuntura Global, vol. 5 n. 1, jan./abr., 2016, p. 19-33. 
União Europeia (UE) a respeito do fenômeno imigratório na região do bloco? Nesse sentido, assume-se como hipótese que a natureza da recente crise migratória de 2015 na Europa é multicausal, agregando aspectos econômicos, sociais e políticos, o que provocou, considerada a magnitude do fluxo imigratório e o arranjo institucional da União Europeia, alterações estratégicas do bloco para a administração das migrações sob conflito político entre os Estados-membros a respeito do tema.

Portanto, o objetivo geral é analisar a natureza da crise migratória na Europa e quais os reflexos políticos dela na União Europeia. Assim, objetiva-se, especificamente: compreender as teorias aplicadas ao campo do fenômeno migratório; verificar o contexto da crise migratória de 2015 na Europa; analisar o arranjo institucionalnormativo e a governança da União Europeia para as migrações internacionais; e refletir sobre as repercussões dessas migrações no contexto político do bloco.

Destarte, trata-se aqui de um exercício científico que almeja produzir inferências descritivas (KING, KEOHANE, VERBA, 1994) a respeito do fenômeno migratório na Europa, cuja metodologia exploratória agregará fatos e dados objetivamente observáveis e coletáveis, com o fim de demonstrar aspectos não verificados pelo senso comum. Por conseguinte, constituindo uma análise de conjuntura, primeiramente pretende-se estabelecer o estado da arte no campo de pesquisa sobre as migrações internacionais, de modo a qualificar o objeto de estudo na arena teórica e viabilizar possíveis inferências causais. Posteriormente, localizado o objeto de estudo no campo teórico, ter-se-á o amparo analítico e sistêmico para qualificar, sob abordagem histórico-política, o contexto da recente crise migratória na Europa, considerando os seguintes níveis de análise: fatores de repulsão; fatores de atração; e rotas e meios pelos quais esses fluxos migratórios se movem.

Compreendido o fenômeno migratório em pauta, ao final dessas duas fases será possível concluir o teste da primeira parte da hipótese sugerida, qual seja, a que trata da natureza da crise migratória na Europa. Na terceira fase, serão identificados os aspectos institucionais na União Europeia, identificando qual a governança do bloco para a questão migratória, evidenciando o espectro normativo-institucional (KRASNER, 1982; KEOHANE; MARTIN, 1995), de modo a identificar as bases do debate político na União Europeia a respeito da imigração. Por conseguinte, na última fase, a análise passará a 
considerar como a crise migratória ecoou na realidade política da União Europeia, fechando o teste da segunda parte da hipótese.

Nessa perspectiva argumentativa e sob essa trajetória metodológica, deve-se ressaltar que o atual sistema internacional apresenta posições e contextos variados em relação às migrações. No lado dos países emissores, ao mesmo tempo em que existem países que interpretam suas diásporas de modo positivo - como a China e a Índia que promovem emigrações e acompanham suas comunidades no exterior - existem também aqueles Estados que buscam restringir a saída de seus nacionais, em especial aqueles com crescimento demográfico negativo. No lado dos países receptores, os extremos também se manifestam, com países mais fechados aos imigrantes - como o Japão e sua defesa de uma sociedade homogênea - e países mais receptivos e que buscam atrair imigrantes, como Canadá, Austrália e Arábia Saudita. Nesse contexto, a questão dos migrantes é antes politizada do que analisada, e a razão trabalha a serviço da posição política e do julgamento, e não o contrário (COLLIER, 2013, p. 11-26).

Nas duas últimas décadas, esse mecanismo tem se refletido, sobretudo, na arena dos fatores econômicos. 0 fluxo majoritário de pessoas de países em desenvolvimento ou de menor desenvolvimento relativo para os países desenvolvidos tem gerado conflitos na esfera trabalhista e ressoado no plano político. Em específico, trata-se do fluxo de migrantes de baixa qualificação para países desenvolvidos e com economias aquecidas, o que gera a antipatia de sindicatos e associações setoriais de trabalhadores desses países recipientes - porque amplia a demanda por emprego, pressionando para baixo os salários - e tal sentimento refratário aos imigrantes é captado por partidos políticos, espalhando elevado conflito sobre o tratamento desses fluxos e transmitindo atritos entre os países receptores e emissores. Esse grau de conflito por vezes provoca a criação, considerando a elevada pressão da questão, de linhas de ajuda ao desenvolvimento para os países emissores, como medida para atenuar o fluxo emigratório destes para as regiões mais desenvolvidas (BERMEO; LEBLANG, 2015, p. 627-632). Entretanto, o hodierno contexto não se trata somente de elementos econômicos e, consequentemente, cooperação para o desenvolvimento econômico não é uma via suficiente, malgrado necessária.

Nesse sentido, a pesquisa aplicada à compreensão das migrações internacionais, ainda que se concentre significativamente em uma perspectiva econômica, avançou para 
considerar diversos elementos. A teoria mais antiga voltada para compreender as migrações internacionais é a abordagem econômica neoclássica, cujo foco, estritamente microeconômico, assumia que basicamente diferenças geográficas nas ofertas e demandas por trabalho provocam fluxos migratórios de regiões de baixos salários para regiões de altos salários; portanto, um indivíduo decide migrar após racionalmente calcular o custo-benefício e o retorno líquido financeiro (MASSEY; et. al., 1993, p. 433444).

Entretanto, fluxos migratórios em massa, tal como aquele que ocorre atualmente para os países europeus, indicam, pelo montante de pessoas em curto espaço de tempo, que não se trata meramente de um elemento econômico, e que, dificilmente tais migrantes realizaram cálculos de custo-benefício ou custooportunidade com o nível de exatidão assumido pelas abordagens econômicas, não obstante tenham possivelmente feito tal reflexão de modo menos acurado. Mais próxima da realidade contemporânea está a abordagem do sistema-mundo, com base nas contribuições de Wallerstein, a qual basicamente assume que as migrações são uma repercussão natural do avanço do capitalismo em países menos desenvolvidos, gerando fluxos de migrantes que buscam nas economias mais prósperas possibilidades de maior renda. Trata-se de o avanço capitalista criar mais liberalismo e mobilidade de capital, bens, serviços e, obviamente, pessoas. (Ibid., p. 444-448).

Já a teoria das redes assume que as redes de migrantes tornam menores o risco e o custo-oportunidade da migração, impulsionando esse fenômeno, na medida em que o candidato à imigrante recebe informação e apoio dos grupos de imigrantes já sediados no país receptor. Por sua vez, a teoria institucional volta-se para aquelas organizações que operam lucros ao oferecer serviços de migração e facilitação de vistos, o que promove fluxos migratórios. Uma outra vertente é a teoria da causa cumulativa, que assume que os motivos para migrar vão se acumulando de uma onda migratória para a outra, por meio do maior fluxo de informação e percepções, somando aspectos econômicos, sociais, políticos e culturais. Uma última perspectiva é a teoria dos sistemas migratórios, que afirma existirem sistemas migratórios compostos de um conjunto de países emissores conectados a um conjunto de países receptores, sendo tais sistemas fluídos e, por corolário, não perenes, já que os contextos social, econômico e político dos 
países emissores e receptores podem mudar, extinguindo aquele fluxo (Id., p. 448-454). Aparentemente essa perspectiva ostenta mais aderência ao atual fluxo na Europa.

Não obstante, o presente trabalho assume uma perspectiva multicausal, na qual diferenças salariais e de renda, fluxo de informações e de riscos, efeitos do capitalismo como sistema-mundo, redes e sistemas migratórios e instituições se complementam para compreender o que ocorre na Europa. Porém, devem-se frisar outros fatores localizados nos países receptores e nos países emissores em tela. No lado dos países emissores, formando a primeira ponta da atual crise migratória, estão países localizados no centro e no norte da África, além daqueles no Oriente Médio. Em sua grande maioria, são países que passaram pela já pretérita Primavera Árabe e não conseguiram sustentar uma trajetória rumo a uma democracia liberal, tampouco operaram estruturas capitalistas articuladas com o provimento de bens e serviços públicos. Tratam-se, em suma, de países que, no vácuo de liderança após os movimentos da dita primavera, caíram em crise institucional e fiscal, agregando-se à temida lista de failed states. Enquadram-se aqui Líbia, Marrocos, Egito, Argélia, Iêmem e Síria, por exemplo, considerando que a este último se agrega a questão do Estado Islâmico.

Outro perfil de países que compõem o conjunto emissor é caracterizado pelo histórico baixo desempenho econômico, gerando abalos das instituições nacionais e ocasionando conflitos armados locais e guerras civis, incluindo aqui Eritreia, Guiné, Gambia e Sudão. Nesse agrupamento de países emissores, tanto considerando aqueles que passaram pela Primavera Árabe como aqueles que não a experimentaram, o quadro político, social e econômico é deteriorado, sendo esse o traço comum que os une e um dos fatores repulsores de pessoas, produzindo emigrantes. 0 produto interno bruto (PIB) da Líbia decresceu 24\% em 2014 e o do Iêmem recuou 0,18\% no mesmo ano. Ainda que alguns países estejam crescendo economicamente, a inflação e o desemprego oprimem o poder aquisitivo, como no Egito que evidenciou crescimento do PIB em 2014 de $2,1 \%$, mas uma inflação de $10 \%$ e taxa de desemprego de 13\%; e o Sudão, com PIB em alta de 3,3\%, inflação de 36,9\% e desemprego em 13,6\%. (INTERNATIONAL MONETARY FUND, 2015a).

Um outro traço marcante no plano dos países emissores são os conflitos armados e as guerras, que se somam ao baixo perfil econômico e social. Aqui se destacam Síria e Iraque, que sofrem o avanço do Estado Islâmico, além de Nigéria, 
pressionada pelo Boko Haram, e o Afeganistão, em situação de conflito com restantes adeptos do Talibã. Aqui se trata de variável importante, vez que, somada aos elementos da esfera econômica, constitui o arranjo do contexto produtor de emigrantes. Essa arena política supera em larga medida as teorias sobre migrações concentradas em uma explicação econômica. Ademais, conecta o quadro geral da política doméstica com a política internacional, gerando os laços complexos da interdependência (KEOHANE; NYE, 2001; KEOHANE; MILNER, 2002) singular dos efeitos migratórios, causando atritos ou lançando a cooperação entre Estados emissores e Estados receptores. Considerando se tratar de grupos terroristas que esgotam as forças institucionais dos governos, o fluxo emigratório desses países em crise política e econômica ganha contornos mais profundos e amplos, superando a capacidade administrativa de lidar com a situação e se assemelhando a uma típica força profunda (DUROSELLE, 2000), transcendendo o conceito de variável dependente e se aproximando de uma variável independente.

Vistos os fatores repulsores no conjunto dos Estados emissores, de modo a construir uma visão sistêmica sobre o fenômeno em análise, deve-se lançar luz nos fatores intervenientes, antes de voltar o olhar para o outro lado do elo do fluxo migratório, os países receptores. Nesse nível destaca-se a proximidade geográfica entre o conjunto dos países emissores e o grupo dos países receptores. Por exemplo, uma das principais rotas conecta Tripoli, na Líbia, com a ilha de Lampedusa, na Itália, perfazendo apenas $319 \mathrm{~km}$.

Destarte, ressaltam-se aqui as principais rotas que conectam as regiões centro e norte da África e Oriente Médio com a Europa, em especial a região do Mediterrâneo. Em geral, duas formas de se chegar à Europa são executadas: a marítima, ligando cidades litorâneas da Líbia, Argélia, Marrocos e Egito às ilhas gregas e italianas, ou mesmo às costas turca e espanhola. Vale frisar aqui que os emigrantes de países na região central da África fazem um primeiro e perigoso percurso terrestre em continente africano até chegar no litoral dos 4 países supramencionados, embarcando em balsas, botes ou barcos para a Europa (FRONTEX, 2015a²). Outra forma é a rota terrestre, cujo trânsito predomina emigrantes do Quênia, Egito, Etiópia e Eritreia, passando pela Síria

\footnotetext{
${ }^{2}$ Após a entrada em vigor em 1995 do Acordo de Schengen, e com a entrada de novos membros em 2004, a União Europeia (UE), a fim de equilibrar o pilar do livre trânsito de pessoas com a segurança do bloco, criou em 26 de outubro de 2004 a Agência Europeia para Gestão da Cooperação Operacional das Fronteiras Externas dos Estados-membros da União Europeia (FRONTEX), cuja missão é promover, coordenar e desenvolver a administração das fronteiras europeias (FRONTEX, 2015b); 
(agregando os nacionais daqueles países aos nacionais deste), e atravessando a Turquia para adentrar o espaço europeu (Ibid.).

A Organização Internacional para Migrações ${ }^{3}$ (OIM) informou que, com dados atualizados até 16 de setembro de 2015, que a rota marítima no Mediterrâneo já soma 473.887 migrantes, dos quais 349.109 chegaram à Grécia $(74 \%$ do contingente migratório) e 121.859 na Itália (26\%). No destino grego, a maioria é composta de sírios (175.375), afegãos (50.177) e paquistaneses (11.289). Já em terras italianas, a população de migrantes é de maioria eritreia (30.708), nigeriana (15.113) e somali (8.790). Esse contingente é o lado de superação dessa história, já que se contabiliza, até a data de produção do presente trabalho, 2.812 mortes no trecho mediterrâneo, das quais 2.620 ocorreram nas rotas que ligam a Líbia às ilhas italianas (OIM, 2015b). Portanto, são essas as rotas de preferência majoritária dos migrantes; entretanto, a chegada na Itália, na Grécia ou na Hungria não significa o fim do fluxo, dado que os países de preferência dos migrantes se encontram além da fronteira desses três Estados. Destacam-se, nesse ínterim, recentes novas rotas dentro da Europa (BBC, 2015), em área rural, em virtude dos bloqueios e proibição de acesso a trens e ônibus da parte dos governos húngaro e grego. Assim, os migrantes, para chegarem aos Estados europeus de destino final - como Reino Unido e Alemanha - estão optando por rotas a pé em campos e áreas rurais, gerando um desafio maior para as autoridades nacionais europeias e a FRONTEX.

Nessa vertente, a proximidade geográfica não atua solitária no universo das variáveis intervenientes dessa tragédia migratória. Mencionam-se aqui os escassos recursos econômicos que os migrantes possuem para realizar a trajetória para a Europa, tornando-os reféns de quadrilhas que operam as linhas ilegais de transferência de migrantes das regiões emissoras para as receptoras (KANTER, 2015). Adicionam-se a isso as condições em que a passagem é realizada, normalmente em pequenas embarcações ou mesmo em simples botes, os quais não são suficientes para garantir segurança perante as ondas do mar mediterrâneo, produzindo desoladoras imagens de corpos pairando nas praias, aguardando a fria identificação e o holofote da mídia internacional, como foi o caso do garoto Aylan Kurdi, de 3 anos, encontrado em praia na

\footnotetext{
${ }^{3}$ A OIM foi estabelecida em 1951 com a missão de assegurar a gestão humana das migrações, promover a cooperação internacional para migrações, atuar na solução de crises migratórias e prover assistência humanitária para os migrantes, refugiados e deslocados internos. A OIM possui 157 Estados-membros (entre ele o Brasil), 10 Estados-observadores e escritórios em 100 países (OIM, 2015a). 
Turquia (WITHNALL, 2015). Fechando o sistema de condicionantes, cita-se o fator psicológico em que esse fluxo migratório ocorre. Nesse nível, eminentemente subjetivo e insondado no artigo em pauta, as condições sociais dos países emissores, a urgência de conflitos armados e o desespero produzem basicamente dois tipos de migrantes: o refugiado, que busca asilo em defesa de sua vida; e os migrantes econômicos, que buscam melhores condições de renda.

Dessa forma, esclarecido o contexto dos países emissores e as condições do fluxo migratório, resta, para fechar o elo desse sistema migratório, considerar os elementos atrativos que tornam a Europa o destino de migrantes africanos, asiáticos e do Oriente Médio. Ademais da já mencionada e conveniente proximidade geográfica, outros elementos exercem força na composição desse fluxo migratório. Nesse nível, frisa-se que afegãos e paquistaneses teriam como opção de destino, em função de proximidade geográfica, terras russas, indianas e mesmo chinesas. Contudo, outros aspectos tornam paisagens europeias mais agradáveis aos olhos dos migrantes.

Em um primeiro plano, destaca-se o quadro econômico de alguns países europeus, indicando maiores chances de empregabilidade. Nessa arena, a taxa de desemprego na União Europeia foi de 10,9\% em 2013, decrescendo para 10,2\% em 2014 (EUROSTAT, 2015). Consoante dados da EUROSTAT, as taxas mais baixas em julho de 2015 estão na Alemanha (4,7\%), República Tcheca e Malta (ambos 5,1\%); e Reino Unido (5,6\%), constituindo um primeiro sinal de atração dos imigrantes pelas economias alemã e inglesa. Quanto à produção de riqueza, o PIB mundial em 2014 cresceu 3,41\%, com previsão de alta em 3,39\% para 2015. O PIB da UE no mesmo período foi de altas de $0,11 \%$ e 1,40\%. Nesse âmbito, as economias alemã e inglesa se destacam, não pelo baixo pelo crescimento do PIB, mas pela estabilidade dessa taxa de crescimento: Alemanha com altas de 1,60\% (2014) e 1,62\% (2015); e Reino Unido com $1,66 \%$ (2014) e 2,55\% (2015).

Quanto à carestia, a taxa de inflação no mundo em 2014 foi de 3,91\%, com perspectiva para 3,45\% em 2015. Nos mesmos respectivos anos, a UE apresenta taxas de $1,53 \%$ e $0,53 \%$, possuindo um perfil econômico menos custoso para consumidor que a média mundial, aspecto importante para um imigrante. Nessa vertente, deve-se destacar novamente Alemanha e Reino Unido, que terão taxas de inflação em 2015 de 0,21\% e 0,12\% respectivamente (FMI, 2015). Destarte, o quadro econômico desses 
países europeus e sua estabilidade macroeconômica permitem maior empregabilidade e ascensão de renda, o que contribui por uma preferência dos imigrantes por essas regiões.

O segundo aspecto relaciona-se à política migratória de cada país do bloco europeu, bem como a posição dos governos a respeito do recente fluxo migratório e o contexto da migração em seus territórios. Nessa arena, esclarece-se que política migratória, apesar dos avanços dos tratados de Nice e de Lisboa, é tema ainda não elevado ao nível do direito comunitário, podendo, por conseguinte, cada Estado-membro do bloco definir seu arcabouço jurídico-político para essa agenda. Em virtude desse aspecto, localiza-se aqui a primeira fonte de conflito no bloco em referência ao fluxo migratório ora analisado. Em específico, o Tratado de Lisboa, vigente desde 2009, estabeleceu que esse tema é de competência partilhada entre Estados-membros e União Europeia, introduzindo a codecisão entre Parlamento Europeu e Conselho Europeu em matéria de migração, bem como uma nova base jurídica que visa promover medidas de integração entre as normas nacionais de cada Estado-membro.

A despeito dessa estrutura ainda intergovernamental, em 2011 a Comissão estabeleceu a Abordagem Global para a Migração e a Mobilidade, por meio da qual firma um esquema geral para as relações da UE com países terceiros em matéria de migração, erguido sobre quatro pilares: a imigração legal e a mobilidade; a imigração ilegal e o tráfico de seres humanos; a proteção internacional e a política de asilo; e a maximização do impacto da migração e da mobilidade sobre o desenvolvimento (UE, 2015, p. 2). Ademais, já em virtude de crescente e rápido afluxo de migrantes na Europa, a UE definiu, em junho de 2014, as "orientações estratégicas da programação legislativa e operacional no espaço de liberdade, segurança e justiça" para o período 2014-2020, tratando-se apenas de orientações gerais para aplicação e consolidação dos instrumentos jurídicos e das medidas políticas já em vigor em matéria de migração. De todo modo, um ponto relevante que deve ser sublinhado aqui se volta para a questão de cotas de recepção e medidas de curto, médio e longo prazo para lidar com súbitos afluxos de migrantes.

Tais aspectos, além de questões relacionadas ao reconhecimento e cadastro de refugiados, passam a encarnar o debate mais incisivo entre os países-membros da União Europeia. Em 13 de maio de 2015, a Comissão esboça sua primeira reação articulada 
para fazer face à crise migratória com a publicação da Agenda Europeia da Migração, pela qual se oferece orientações de médio e longo prazo, tais como reduzir os incentivos à migração irregular; gerir as fronteiras, salvando vidas e garantindo a segurança; desenvolver uma forte política comum em matéria de asilo, bem como rever o Regulamento de Dublin em 20164, a fim de torná-lo mais célere e menos burocrático (MARQUES, 2015). Entre as medidas de emergência, a Comissão triplicou os recursos disponíveis em 2015 e para 2016 da FRONTEX, iniciou processo para estabelecer um mecanismo permanente e integrado de tratamento para requerentes de asilo e, por fim, no âmbito da Política Comum de Segurança e Defesa, estabeleceu processo negociador para desenhar operação coordenada com vistas a desmantelar as redes de passadores e combater o tráfico de migrantes (Id., p. 3).

Nota-se que, substancialmente, a UE, no curto prazo, conseguiu alcançar medidas possíveis, quando considerados os limites de atuação do bloco em matérias de competência partilhada. Todavia, persiste forte conflito entre os Estados-membros a respeito das cotas de recepção de migrantes, sobre os encargos políticos, financeiros e econômicos que a entrada em massa causa nas economias europeias, além de transparecer um aspecto vital no processo europeu de integração. Trata-se do próprio desenvolvimento e continuidade da integração regional rumo à consolidação de uma ordem integralmente calcada no esquema jurídico comunitário. Em essência, a UE encontra-se numa situação curiosa, na qual a integração não foi concluída e, portanto, ao persistir aspectos intergovernamentais no bloco, impactos exógenos geram elevado grau de conflito, sendo esse o final elemento da presente análise.

É um mecanismo semelhante ao que ocorreu no plano econômico. Neste, houve uma crise econômica originada de fora, a inadimplência generalizada do crédito subprime no mercado imobiliário dos Estados Unidos, e que, por meio de fluxos financeiros, contaminou a estrutura bancária da Europa, gerando pressões sobre juros e sobre a dívida pública dos Estados europeus. Embora a política monetária na UE tenha migrado para o âmbito comunitário, a política fiscal ainda reside como competência exclusiva dos Estados-membros. Assim, ao receber o impacto exógeno da crise econômica norte-americana, a economia do bloco apresentou diversas reações (em

\footnotetext{
${ }^{4}$ O Regulamento de Dublin surgiu em 1990, incorporando os preceitos da Convenção das Nações Unidas sobre o Estatuto dos Refugiados de 1951, entrando em vigor somente em 1997 e sendo aplicado nos 28 países da União Europeia, a que se somam Suíça, Islândia, Noruega e Liechtenstein.

Conjuntura Global, vol. 5 n. 1, jan./abr., 2016, p. 19-33. 
especial em relação ao caso grego), em virtude dessa dissonância de competências no plano econômico. 0 mesmo mecanismo se processa na questão aqui em pauta. A crise migratória é um elemento exógeno ao bloco europeu e, em virtude da competência partilhada em matéria de migração e asilo, é esperado que se manifestassem diferentes percepções dos Estados-membros sobre esse fenômeno. Portanto, o conflito interno é a primeira consequência de impactos exógenos críticos ao bloco.

E tal como ocorre no plano econômico, a crise migratória levanta, para além de questões relacionadas a cotas e medidas de segurança na fronteira, uma reflexão fundamental para a UE: diante dessas crises, que fogem ao controle direto dos Estados, o processo de integração na Europa ou deveria avançar - o que permitiria respostas rápidas e uníssonas, gerando estabilidade interna e baixo conflito -, ou a integração e o direito comunitário deveriam ser repensados, liberando os países para adotarem posições unilaterais, o que gera maior instabilidade regional e desgaste do bloco. A primeira opção exige tempo negociador, enquanto a segunda gera custos assimétricos para os Estados. Enquanto o bloco europeu não resolver essa dissonância arriscada, em que matérias do mesmo plano estão diversamente distribuídas entre competências comunitárias, partilhadas e estatais, o bloco continuará em conflito interno na medida em que recebe tais impactos exógenos sistêmicos.

Por fim, cabe aqui mencionar um aspecto essencial da governança da UE para a migração internacional. Verificam-se, entre os quatro pilares vistos da Abordagem Global para a Migração e a Mobilidade, um em específico que expõem a percepção do bloco relacionada à securitização do tema migratório. 0 pilar para a imigração ilegal e o tráfico de seres humanos, que destaca três questões: a imigração ilegal, considerando aqui a entrada de terroristas e pessoas que podem oferecer ameaça à UE; os refugiados e a questão do asilo, que relacionam a UE aos regimes internacionais de direitos humanos; e as organizações criminosas que traficam pessoas, as quais podem evidenciar a fragilidade nas fronteiras do bloco.

Dado esse contexto, já no Acordo de Schengen, assinado em 1985 e que estabelece a livre circulação de pessoas entre os países signatários, a questão da imigração ilegal como ameaça à segurança dos Estados-membros é prevista em seu art. 7ํ. Mencionam-se também os esforços no âmbito da política externa e de segurança da UE, frisando a EUROPOL, o Serviço Europeu de Polícia, cuja missão é garantir a 
segurança do bloco pelo combate ao crime internacional e ao terrorismo (EUROPOL, 2016), incluindo aqui a investigação sobre e o combate às redes de tráficos de pessoas e rotas de imigração ilegal, agindo em complementação às ações da FRONTEX. Malgrado a securitização da migração internacional permeie diversas legislações e agências da União Europeia, ela se restringe à criminalização da imigração ilegal e a ações meramente cooperativas, agregando esforços para obstar a entrada ilegal, aumentar o controle das fronteiras do bloco e combater a ação de organizações criminosas. Ademais, essas medidas não forçam ações comunitárias para o tratamento de fluxos migratórios em massa. Frisa-se que, estando políticas migratórias ainda sob o véu soberano dos Estados-membros, a diferença entre elas evidencia também as diferentes percepções sobre a ameaça que oferecem os fluxos migratórios, gerando diversas preferências políticas e, por corolário, o conflito político (WENDT, 1992).

\section{Considerações Finais}

A análise de conjuntura aqui implementada em quatro fases metodológicas a respeito da crise migratória na Europa gerou algumas inferências descritivas e causais, as quais cabem ser relacionadas. Primeiramente, observou-se que as teorias aplicadas ao tema apresentam contexto complementar, porquanto elas analisam elementos específicos do fenômeno migratório. Consequência desse aspecto é que a abordagem multicausal é a mais adequada para aplicar ao objeto de pesquisa aqui em pauta. Segundo, verificou-se que o esquema do fluxo migratório para a Europa possui fatores de repulsão e de atração eminentemente políticos e econômicos, deixando em segundo plano aspectos culturais e normativos. Verificou-se também que o arranjo institucional hodierno da União Europeia estabelece específicas medidas cooperativas e partilhadas entre os Estados-membros no trato da questão migratória, mas esse tema permanece sob a administração soberana dos mesmos Estados, expondo diferentes preferências e abrindo conflito político para a solução da recente crise migratória.

Conclui-se, portanto, pela procedência da sugerida hipótese. Destarte, a crise migratória, de natureza multicausal e exógena, além de seu intenso e contínuo fluxo, desencadeou conflito político entre os Estados-membros da União Europeia, a qual reagiu no curto prazo com alterações estratégicas possíveis, mas evidenciou divergentes preferências entres os membros, dado que o arcabouço normativo não estabelece 
parâmetros comunitários para a administração em longo prazo dessas crises, restringindo-se apenas na ação cooperada e reativa para o combate de crimes relacionados ao processo migratório.

\section{REFERÊNCIAS}

AGÊNCIA EUROPEIA DE GESTÃO DA COOPERAÇÃO OPERACIONAL NAS FRONTEIRAS EXTERNAS DOS ESTADOS-MEMBROS DA UNIÃO EUROPEIA. Western Mediterraneam Route. Disponível em: $<$ http://frontex.europa.eu/trends-and-routes/westernmediterranean-route/>>. Acesso em: 19 set. 2015.

. Origem. Disponível em: << http://frontex.europa.eu/about-frontex/origin/>>. Acesso em: 19 set. 2015.

BBC. Migrant crisis: New routes sought amid impasse in Balkans. 19 set. 2015. Disponível em: << http://www.bbc.com/news/world-europe-34300227>>. Acesso em: 19 set. 2015;

BERMEO, Sarah Blodgett; LEBLANG, David. Migration and Foregin Aid. International Organizatio. Vol. 69. N. 03. Jun. 2015. P. 627-657. DOI: 10.1017/S0020818315000119

COLLIER, Paul. Exodus: How Migration is Changing Our World. New York: Oxford University Press, 201. 309 p.

DUROSELLE, Jean-Baptiste. Todo império perecerá: teoria das relações internacionais. Brasília: Editora UnB: Imprensa Oficial, 2000. 483 p.;

EUROPOL. Europol's Operational Activities. Disponível em: << https://www.europol.europa.eu/content/page/mandate-119 >>. Acesso em: 1으 mai. 2016.

EUROSTAT. Total Unemployment Rate. Disponível em: $<<$ http://ec.europa.eu/eurostat/tgm/table.do?tab=table\&init=1\&language=en\&pcode $=\mathrm{t}$ sdec450\&plugin=1 >>. Acesso em: 23 set. 2015;

IMF. Report for Selected Countries and Subjects. Disponível em: $<<$ http://www.imf.org/external/pubs/ft/weo/2015/01/weodata/weorept.aspx?pr.x=5 $5 \&$ pr. $y=10 \&$ sy $=2013 \&$ ey $=2020 \&$ scsm $=1 \&$ ssd $=1 \&$ sort $=$ country $\& d s=. \& b r=1 \& \mathrm{c}=128 \% 2 \mathrm{C}$ 142\%2C172\%2C134\%2C144\%2C112\%2C111\&s=NGDP RPCH\%2CPCPIPCH\&grp=0\&a =>>. Acesso em: 23 set. 2015;

Report for Selected Countries and Subjects. Disponível em: $<<$ http://www.imf.org/external/pubs/ft/weo/2015/01/weodata/weorept.aspx?pr.x=4 $6 \& \mathrm{pr} . \mathrm{y}=8 \& \mathrm{sy}=2013 \& \mathrm{ey}=2020 \& \mathrm{scsm}=1 \& \mathrm{ssd}=1 \& \mathrm{sort}=$ country \&ds $=. \& \mathrm{br}=1 \& \mathrm{c}=512 \% 2 \mathrm{C} 6$ 82\%2C612\%2C686\%2C564\%2C469\%2C433\%2C732\%2C463\%2C744\%2C446\%2C672 \%2C474\&s=NGDP RPCH\%2CPCPIPCH\%2CLUR\&grp=0\&a=>>. Acesso em: 23 set. 2015;

KANTER, James. E.U. Agrees to Naval Intervention on Migrant Smugglers. The New York Times. Bruxelas. 18 mai. 2015. Disponível em: $<<$ http://www.nytimes.com/2015/05/19/world/europe/european-union-humantrafficking-military.html? $\mathrm{r}=0>>$. Acesso em: 19 set. 2015; 
KEOHANE, Robert 0.; MARTIN, Lisa L. The Promise of Institutionalist Theory. International Security. vol. 20, n. 1. (Verão, 1995). p. 39-51.

KEOHANE, Robert O.; MILNER, Helen V. (org.). Internationalization and Domestic Politics. Cambridge: Cambridge University Press, 2002. 308 p.;

KEOHANE, Robert O.; NYE, Joseph S.. Power and Interdependence. 3 ed. New York: Longman, 2001. 334 p.;

KING, Gary; KEOHANE, Robert O.; VERBA, Sidney. Designing Social Inquiry: scientific inference in qualitative research. Cambridge: Cambridge University Press, 1994. 245p.

KRASNER, Stephen D. Regimes and the limits of realism: regimes as autonomous variables. International Organization. vol. 36. n. 2. Março 1982. p. 497-510.

MARQUES, Francisco. Regulamento de Dublin começa a abrir brechas na União Europeia. Euronews. [S. l.]. 17 set. 2015. Disponível em: $<$ http://pt.euronews.com/2015/09/10/migracao-regulamento-de-dublin-comeca-aabrir-bechas-na-uniao-europeia/> Acesso em: 28 out. 2015;

MASSEY, Douglas S.; et. all. Theories of International Migration: a review and appraisal. Population and Development Review, Vol. 19, n. 3. Set., 1993. p. 431-466;

ORGANIZAÇÃO INTERNACIONAL PARA MIGRAÇÕES. A Record 432,761 Migrants, Including Refugees Seeking Asylum in the European Union Have Crossed the Mediterranean so far in 2015. Disponível em: $<<$ http://missingmigrants.iom.int/en/record-432761-migrants-including-refugeesseeking-asylum-european-union-have-crossed-mediterranean $>>$. Acesso em: 19 set. $\underline{2015}$; set. 2015.

About IOM. Disponível em: << http://www.iom.int/about-iom>>. Acesso em: 19 . Mediterranean Update Missing Migrants Project: updated 17 September 2015. Disponível em: $<<$ http://www.iom.int/sites/default/files/infographic/Mediterranean Update 17 Septem ber.pdf $>$ >. Acesso em: 19 set. 2015.

PARK, Jeanne. Europe's Migration Crisis. New York: Council on Foreign Relations, 2015. Disponível em: <<http://www.cfr.org/migration/europes-migration-crisis/p32874>>. Acesso em: 4 nov.2015;

THE SCHENGEN ACQUIS. Agreement between the Governments of the States of the Benelux Economic Union, the Federal Republic of Germany and the French Republic on the gradual abolition of checks at their common borders. 14 de junho de 1985. Luxemburgo. Disponível em: < http://eur-lex.europa.eu/collection/eu-law/treatiesother.html\#new-2-26>>. Acesso em: 1ำ mai. 2016.

TRATADO Sobre o Funcionamento da União Europeia. 01 dezembro 2009. Disponível em: $<$ http://europa.eu/pol/pdf/consolidated-treaties pt.pdf $>>$. Acesso em: 27 out. 2015;

UNIÃO EUROPEIA. Fichas Técnicas sobre a União Europeia: política de imigração. Bruxelas, $2015 . \quad 5 \quad$ p. $\quad$ Disponível em: < http://www.europarl.europa.eu/ftu/pdf/pt/FTU 5.12.3.pdf $>>$ Acesso em: 23 set. 2015; 
WENDT, Alexander. Anarchy is what states make of it: the social construction of power politics. International Organization, vol. 46, n. 2, 1992, p. 391-425.

WITHNALL, Adam. Aylan Kurdi's story: How a small Syrian child came to be washed up on a beach in Turkey. The Independent. Londres. 3 set. 2015. Disponível em: <http://www.independent.co.uk/news/world/europe/aylan-kurdis-story-how-a-smallsyrian-child-came-to-be-washed-up-on-a-beach-in-turkey-10484588.html>. Acesso em: 19 set. 2015. 